\title{
Governing knowledge commons in Caribbean disaster management: A comparative institutional analysis
}

\author{
Maurice McNaughton* and Lila Rao \\ Mona School of Business and Management, The University of the West Indies, Mona, Jamaica
}

\begin{abstract}
This paper is based on research conducted as an initiative under the Open and Collaborative Science in Development Network (OCSDNet) to explore new innovative mechanisms that can enhance collaborative disaster recovery planning, knowledge management, and learning in the Caribbean. The need for enhanced knowledge management to mitigate disaster risk through the sharing of information and knowledge is a strategic imperative of the Caribbean Disaster Management community. The devastation of the 2017 Hurricane season was a stark reminder of the Caribbean' vulnerability to natural disasters and underscores the urgency for Collective Action in the common challenge to mitigate the effects of these disasters and to preserve the sustainability and livelihoods of the region and it's citizens. We employ a preliminary conceptual application of the Knowledge Commons/IAD Framework to illustrate how this kind of institutional analytic process can illuminate and inform strategy, governance and desirable collective action, as well as the merits of alternative enabling technologies. The study contributes to arguments challenging the neutrality of infrastructure for collective action. It highlights the importance, and perhaps imperative, of an institutional approach to the design and implementation of socio-technical systems.
\end{abstract}

Keywords: Knowledge Commons, Disaster Recovery Planning, Governance, Controlled Vocabularies, Caribbean

\section{Introduction}

The Open Science paradigm is broadly characterized by a multitude of emergent trends and influences that continue to disrupt and transform conventional notions about the process, mechanisms and roles involved in knowledge creation and dissemination. Factors ranging from the increased participation of the non-scientific public, democratic parity in access to knowledge resources and greater efficiency in knowledge production through open models of collaboration, manifest the changing nature of scientific practice, and is underpinned by the pervasive influence of ICTs [6]. One of the key technological artifacts that is increasingly prevalent in the Open Science paradigm is the emergence of the Knowledge Commons.

Commons, as a general term, refers to a resource shared by a group of people, whereas knowledge, as a specific type of resource, refers to a broad set of intellectual and cultural artifacts. Ostrom [10] deliberately emphasizes the essence of "Commons" as being not simply an inanimate pooled-collection of artifacts, but rather " a commons is a shared resource that is vulnerable to social dilemmas". This notion is captured by Frischman et al. [7] in their definition of the knowledge commons as "the institutionalized community governance of the sharing and, in some cases, creation, of information, science, knowledge,

\footnotetext{
${ }^{*}$ Corresponding author. E-mail: maurice.mcnaughton@uwimona.edu.jm.
} 
data, and other types of intellectual and cultural resources" thus emphasizing the governance aspect and institutional character of the commons.

This paper is based on research conducted as an initiative under the Open and Collaborative Science in Development Network (OCSDNet) ${ }^{1}$ to explore new innovative mechanisms that can enhance collaborative disaster recovery planning, knowledge management, and learning in the Caribbean. The knowledge broker provides a technical solution for the integration of silos of knowledge as it relates to disaster management/recovery, by providing a common semantic reference for knowledge resources and artifacts distributed throughout the region, thus allowing for the emergence of a distributed knowledge commons.

Much of the emergent thinking about the characteristics of the knowledge commons, it's utility and requisite governance practices is drawn from references to the corresponding theories about natural resource systems governed as commons such as fisheries, grazing pastures, forests, and irrigation systems, etc. Ellinor Ostrom and various collaborators establish much of the intellectual pedigree in which this work is rooted $[13,14]$. Notwithstanding the now acknowledged conceptual flaws, Hardin's seminal "Tragedy of the Commons" (1968) is one of the important anchors in this intellectual tradition. With many of these contributions based on "thought experiments" and conceptual frameworks, there is still a call for empirical studies of real-world commons that help to illuminate when and how knowledge commons governance work - and when it doesn't [7,10]. As Hess \& Ostrom succinctly notes, "[] study after study demonstrates, there is no one solution to all commons dilemmas". This paper thus responds to the call for more empirical research on emerging knowledge commons and studies that help to validate the application of analytic frameworks such as the knowledge commons research framework [7] in different contexts.

The primary objective of this paper is to explore and evaluate the effects that the introduction of the electronic knowledge broker [4], can have on the efficacy and coordination efficiency of the knowledge commons in the Caribbean Disaster Management community. The specific context within which this research is situated provides an interesting domain for examining the characteristics, governance and patterns of interactions within a knowledge commons. Given the common Caribbean vulnerability to, and experience with natural disasters, there is a strong regional commitment to collaboration around comprehensive disaster management and the sharing of knowledge resources, artifacts and coordination.

However, as the research highlights, even within a domain where the actors have strong intersecting interests, minimal competitive incentives, and are generally amenable to open and collaborative solutions to common problems, there are persistent barriers that constrain the effectiveness of knowledge commons. For example, currently in Disaster Recovery Planning, a number of institutions/entities in the region are developing documents and databases related to disaster management/recovery. While there seems to be an active willingness to share these resources, the primary challenge with the efficacy of this de facto "knowledge commons" is standardization, coordinated production and knowing what knowledge resources exists ("How do we know what we know?"). There is no central knowledge authority or directory that someone can go to find out what resources are available and thus they continue to exist in silos with limited sharing. Perhaps, references to the "tragedy of the anticommons" which contemplates the circumstances under which resources are inefficiently underutilized rather than over utilized, as in the more familiar commons setting, may offer some insights in this regard.

The remainder of this paper is structured as follows: Section 2 provides a brief overview of some of the salient literature on Knowledge Commons, and mechanisms for evaluating their attributes and

\footnotetext{
${ }^{1}$ http://ocsdnet.org/
} 
governance characteristics. We examine, in particular, Ostrom's Institutional Analysis and Development Framework (IAD) and derivative applications $[7,9,12,15]$ to various types of commons and related communities; Section 3 applies the IAD to a specific empirical context, the Caribbean Disaster Management community, and presents a conceptual comparative institutional analysis of the relative merits of two distinct technology approaches to building an effective knowledge management system. In Section 4, we highlight the merits of this type of institutional analysis and the insights and implications it suggests for approaches to the planned implementation of a knowledge management system for the regional disaster management community. Some concluding observations and considerations for continued research are outlined.

\section{Literature review}

\subsection{Knowledge commons}

The notion of the Commons as an economic institution in its own right was elevated after Garret Hardin's seminal "The Tragedy of the Commons", published in 1968 [8]. Although Hardin's "Tragedy" predicts a failure of collective action, absent one of the traditional governance mechanisms of private property or public goods, the subsequent work of commons scholars in the natural resource arena led by Ellinor Ostrom and various collaborators suggest otherwise, and have established much of the intellectual pedigree in which this academic stream is rooted $[13,14]$. These studies lead to the identification of a general-purpose set of design principles (see [13], 90-102), if commons as a governance institution is to effectively address the essential core issues of equity, efficiency and sustainability.

Fascination with this discourse has been amplified in recent times with the widespread adoption of ICTs and the pervasive effects of the Internet in particular, leading to the emergence of the Knowledge Commons as a specific variant of the Commons, manifesting idiosyncratic characteristics and a more complex set of social dilemmas [3,7,12,15]. Frischman et al. [7] offer a definition of the knowledge commons as "the institutionalized community governance of the sharing and, in some cases, creation, of information, science, knowledge, data, and other types of intellectual and cultural resources". They emphasize the idea that while this applies collectively to resources, a group or community of people, the Commons does not denote the elements themselves, but rather the institutional arrangement of these elements. This is a particularly important nuance for the knowledge commons in which typically, participants not only share existing resources but also engage in defining and producing those resources, making it impractical, if not impossible, to separate the attributes of the managed resources from the attributes of the community that produces and uses them [7]. In the case of Caribbean Disaster Management, the community itself, is as valuable as the knowledge artifacts, by way of expertise, empathy and responsiveness in the aftermath of a Disaster.

Several other distinct idiosyncrasies of the knowledge commons, as compared with natural commons, are highlighted by Frischman et al. [7] as follows:

(a) While natural resource commons typically seek to allocate consumption and preserve resources, knowledge commons must address the coordination requirements across a range of production, dissemination and consumption activities. Hence social dilemmas in these "constructed commons" often exist more so in incentivizing the contribution and sharing of knowledge rather than the risk of congestion or overconsumption. 
(b) Given the nonrivalrous and nonexcludable character of knowledge resources, knowledge commons must confront questions of openness and the dynamics of sharing both within and outside the defined commons community.

(c) Nonrivalry of knowledge and information resources may be associated with rivalrous inputs and outputs such as time, money and reputation, leading to potentially contentious issues in acquiring and distribution these resources among members of the commons community.

These nuances become apparent and relevant to our subsequent empirical Case analysis.

\subsection{Evaluating knowledge repositories}

According to [7], these distinctive attributes of the knowledge commons require significant engagement with the specific narrative of the community, given the basic assumption that each actor begins from a position of rational self-interest. We therefore turn to several studies of electronic information repositories such as knowledge management (KM) systems and document management (DM) systems that primarily address the behaviors of participants as the unit-of-analysis, and their motivations/incentives to collaborate, contribute and share knowledge artifacts, and provide important insights to the social dilemmas confronting knowledge commons [1,2,11].

Kankanhalli et al. [11] point to the failure of KM initiatives due to the reluctance of employees to share knowledge through knowledge management systems (of which their particular focus is on electronic knowledge repositories (EKR)). They use both the social exchange theory and the social capital theory to formulate and test a theoretical model to explain EKR usage by knowledge contributors. The model was validated through a large scale survey of public sector organizations and it was found that self-efficacy and enjoyment in helping others significantly impact the EKR usage by knowledge contributors.

Bock and Kim [1] seek to develop an understanding of the factors affecting the individual's knowledge sharing behavior in an organisation context. They recognize the importance of knowledge sharing and the growing interest in this area by many senior management. They draw on a number of theories including the social exchange theory, self-efficacy, and theory of reasoned actions. They surveyed employees of large public organisations and found that expected associations and contribution are the major determinant of an individual's attitude toward knowledge sharing. Interestingly they found that expected rewards was not significant to the attitude toward knowledge sharing.

Chiu et al. [2] study focuses on virtual communities and the willingness of members to share knowledge with other members. It is imperative that for these virtual communities to have any value the richness of the knowledge is key, and that this knowledge must be member generated. Thus, it is essential that studies must be conducted to explain why individuals elect to share or not to share knowledge with other community members when they have a choice. They also used the Social Capital Theory but with the Social Cognitive Theory to develop and test a model for investigating the motivations behind people's knowledge sharing in virtual communities. The study found that community-related outcome expectations play an important role underlying knowledge sharing in terms of both quantity and quality, while personal outcome expectations have a negative but insignificant effect on quantity of knowledge sharing.

The insights derived from these studies inform the design of a baseline survey of the Caribbean Disaster Management community and their knowledge attitudes and practices as described in Section 3.2. 


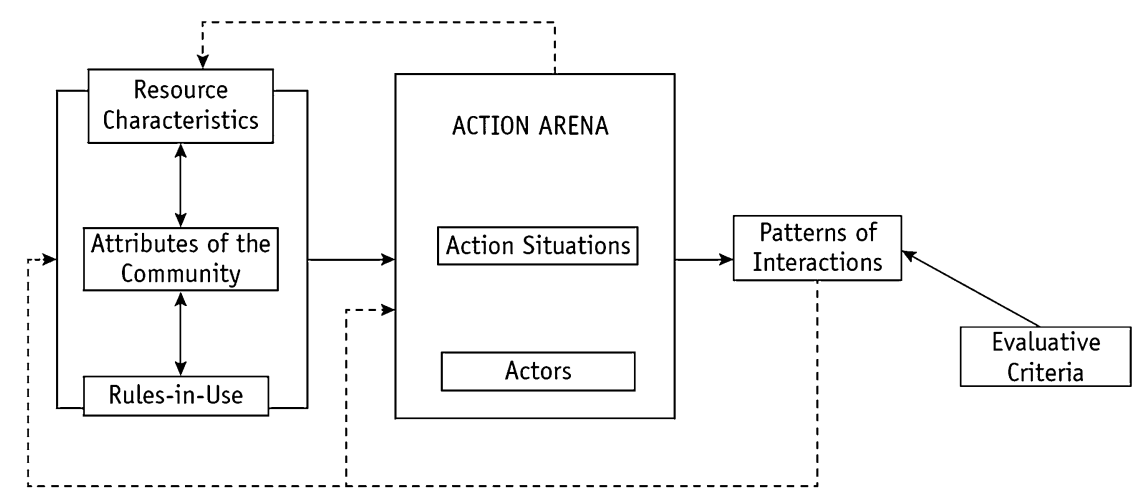

Fig. 1. The Knowledge Commons (IAD) Framework. Source: Frischman et al. [7].

\subsection{Analyzing knowledge commons - IAD framework}

The Institutional Analysis and Development (IAD) framework was developed by Elinor Ostrom and collaborators to provide a general-purpose comparative method of institutional analysis for studying commons arrangements in the natural environment [13]. According to Hess and Ostrom [10], the framework is well suited for analysis of resources where new technologies are developing at a rapid pace, such as the new ICTs that have redefined knowledge communities. It is not only applicable to descriptive analysis, but "... is an appropriate place to start when trying to think through the challenges of creating new form of commons such as a new digital repository within an organization..."

Frischman et al. [7] have taken account of the distinct idiosyncrasies of the knowledge commons in their adaptation of the IAD to the Knowledge Commons Framework (see Fig. 1), which reflects the more complex relationships among knowledge resources, community participants, and governance structures. This is evident, for instance, in the case of Caribbean Disaster Management, where knowledge artifacts such as Disaster Recovery Plans are a function of both standards set by the Governing body as well as the unique local circumstances of the countries participating in the CDM community. [7] describes the application of the framework to the examination and analysis of specific empirical contexts using a systematic cluster of inquiries. Schweik [15] illustrates the application of the approach in the comparative analysis of Open Source Commons institutions, while Morell [12] applies the approach in examining online communities engaged in the creation of digital commons. [12] considers the enabling ICT infrastructure as part of the governance mechanism, rather than as an aspect of the resource characteristics of the commons, hence challenging the neutrality of infrastructure for collective action. This idea is particularly interesting for this study, where, in Section 3.4, we employ the IAD systematic approach to comparative institutional analysis, while examining the relative merits of alternative technology solution approaches to the knowledge management challenges of the Caribbean Disaster Management community.

\section{Case - Caribbean disaster management}

\subsection{Institutional context}

In the Caribbean, the Disaster Management community is well organized, with the Caribbean Disaster Emergency Management Agency (CDEMA) designated as a regional inter-governmental agency for disaster management in the Caribbean Community (CARICOM). CDEMA's mandate is to fully take up 
its role as facilitator, driver, coordinator and motivating force for the promotion and engineering of Comprehensive Disaster Management (CDM) in all Participating States. CDEMA is supported and actively engages with a network of national disaster management agencies. For example, in Jamaica the Office of Disaster Preparedness and Emergency Management (ODPEM) is the main body responsible for coordinating the management of the various types of disasters while in St. Vincent and the Grenadines it is the National Emergency Management Office (NEMO) who is assigned the role of activating the community on a countrywide basis to deal with disasters. CDEMA is governed through a regional structure ${ }^{2}$ consisting of the Council, a Technical Advisory Committee (TAC) and the Coordinating Unit:

- The CDEMA Council is the highest level of governance of CDEMA and determines policies and major decisions on its operations.

- The Technical Advisory Committee (TAC) is the technical and programmatic advisory arm of the CDEMA and comprises of the National Disaster Coordinators and representatives of specialized regional organizations, whose programmes are directly related to the regional disaster management agenda.

- The Coordinating Unit is managed by an Executive Director who is appointed by the Council, and has responsibility for the management and administrative functions of the organization, including research, education and ICT.

Given its mandate CDEMA represents a key knowledge actor within the CDM Community and knowledge management (KM) is seen as one of the strategic priorities for the community, as reflected in Outcome 2 of the Comprehensive Disaster Management [5], which speaks to the need for enhanced knowledge management to understand disaster risk through the sharing of information and knowledge. Two significant institutional initiatives within CDEMA's 5-year strategic program in keeping with these priorities are:

(a) "Enhancing Knowledge \& Application of Comprehensive Disaster Management (EKACDM)", a research project that has as one of its key outcomes "The creation of a regional network which generates, manages, and disseminates knowledge on disaster management".

(b) CDEMA is currently in the process of implementing the Caribbean Risk Information System $(\mathrm{CRIS})^{3}$ as a multifaceted virtual platform that will host an electronic repository of risk management data and information in response to the perceived gaps in the existing de facto knowledge commons in the CDM Community.

\subsection{Baselining the CDM knowledge ecosystem}

While the Caribbean Disaster Management Community has a comprehensive and mature institutional framework in terms of governance mechanisms and reporting relationships throughout the Caribbean, there are deficiencies in the management and sharing of knowledge resources across the Community as acknowledged by the following excerpt from CDEMA's 2014-2024 Strategic Plan, page 14 (highlights added for emphasis):

In a broader context, information about disaster preparedness in case of an emergency, disaster management plans, policies and guidelines have been in existence and accessible for many years.

\footnotetext{
${ }^{2}$ http://www.cdema.org/index.php?option=com_content\&view=article\&id=47\&Itemid=60

${ }^{3} \mathrm{http}: / /$ www.cdema.org/index.php?option=com_content $\&$ view $=$ article $\&$ id $=1577 \&$ Itemid=576
} 
However, communities have been severely affected by disasters due to lack of adequate coping capacity. This may be attributed to limited access to resources to address risk exposure. In order to enhance the information sharing and management of the knowledge generated from various sources, it is highly essential to closely network the organizations/institutions and moreover people working at the community level to increase resilience. The network of institutions will create a common platform and enable its stakeholders and people to capture, organize, share and reuse the knowledge generated in the area of disaster management.

To unpack this issue further, a baseline survey was designed to assess the state of attitudes and practices of members within the Disaster Management community to share knowledge resources with other members of this community. This is an important step of the process in determining the effect the implementation of the Electronic Knowledge Repositories will have on the willingness of the members the Caribbean Disaster Management community to share and contribute to the knowledge resources of the community.

Given this objective, 16 constructs from existing literature related to Knowledge Sharing [1,2,11] were synthesized into a survey instrument. Kankanhalli et al. [11] used both Social exchange Theory and Social Capital Theory to explain electronic knowledge repositories (EKR) usage by knowledge contributors. Chiu et al. [2] used Social Cognitive Theory and Social Capital Theory to investigate the motivations behind people's knowledge sharing in virtual communities. Finally, Bock and Kim [1] used Social Exchange Theory, Self-Efficacy and Theory of Reasoned Action to understand the factors affecting the individual's knowledge sharing behavior in the organizational context. They included a construct for IT usage and this was deemed to be extremely important given the diversity of members in the Caribbean Disaster Management Community. The relevant constructs (see Table 1) from the existing literature were used to design a questionnaire that will be administered to the members of the Disaster Management Community throughout the Caribbean region with the support of the Caribbean Disaster and Emergency Management Agency (CDEMA).

\subsection{Conceptual application of the knowledge commons (IAD) framework}

The appropriately termed Institutional Analysis and Development Framework finds application in both analysis of existing types of commons, as well as in commons design for future desired states. Hess/Ostrom [9] suggest, for instance, that the "Action Arena" (see Fig. 1) is the "appropriate place to start when trying to think through the challenges of creating a new form of commons such as a new digital repository within an organization".

\subsubsection{CRIS - Caribbean risk information system}

In response to the need for enhanced knowledge management as a strategic priority, the Caribbean Risk Information System (CRIS) is conceived as a multifaceted virtual platform that hosts risk management data and information accessible to stakeholders to facilitate analysis, research, greater awareness of risk management and climate change adaptation in the region. Prior regional efforts at similar ICT initiatives have been unsuccessful due to a number of perceived challenges:

- Absence of data and information sharing protocols among agencies;

- Lack of standardization (minimum) of datasets leading to incompatibility of databases to facilitate research, etc.;

- Irregular or un-sustained hosting capacities;

- Poor access to, or limited understanding of use of, data and information; 
Table 1

Constructs used in the design of the questionnaire

Construct $\quad$ Item Wording/Measure and Code

Loss of Knowledge Power (LOKP)

Kankanhalli et al. [11]

Codification Effort (CEFF)

Kankanhalli et al. [11]

Community Reward (CREW)

Kankanhalli et al. [11]

Image (IMAG)

Kankanhalli et al. [11]

Reciprocity (RECP)

Kankanhalli et al. [11]
- Sharing my knowledge resources makes me lose my unique value to the Disaster Management Community

- Sharing my knowledge resources makes me lose my power base in the Disaster Management Community

- Sharing my Disaster Management knowledge resources makes me lose those knowledge resources that makes me stand out with respect to others

- Sharing my Disaster Management knowledge resources makes me lose those knowledge resources that no one else has

- I do not have the time to convert my knowledge resources into a format to share with others

- It is laborious to codify my knowledge resources into a format suited for sharing

- The effort is high for me to codify my knowledge resources into a format suited for sharing

- I am worried that if I share my knowledge resources, I will have to spend time answering follow up questions

- I am afraid that my sharing of knowledge resources will evoke additional clarifications or requests for assistance

- It is important to get a better work assignment when I share my knowledge resources

- It is important to be promoted when I share my knowledge resources

- It is important to get a higher salary when I share my knowledge resources with Disaster Management community members

- It is important to get a higher bonus when I share my knowledge resources with Disaster Management community members

- It is important to get more job security when I share my knowledge resources with Disaster Management community members

- Sharing my knowledge resources improves my image within the Disaster Management Community

- Disaster Management Community members who share their knowledge resources have more prestige than those who do not

- Sharing my knowledge resources improves the Disaster Management community members recognition of me

- When I share my knowledge resources the Disaster Management community members respect me

- When I share my knowledge resources my superiors praise me

- When I share my knowledge resources, I believe that I will get an answer for giving an answer

- When I share my knowledge resources, I expect somebody to respond when I am in need

- When I contribute knowledge resources, I expect to get back knowledge resources when I need them

- When I share my knowledge resources, I believe that my future queries for knowledge resources will be answered
(LOKP1)

(LOKP2)

(LOKP3)

(LOKP4)

(CEFF1)

(CEFF2)

(CEFF3)

(CEFF4)

(CEFF5)

(CREW1)

(CREW2)

(CREW3)

(CREW4)

(CREW5)

(IMAG1)

(IMAG2)

(IMAG3)

(IMAG4)

(IMAG5)

(RECP1)

(RECP2)

(RECP3)

(RECP4) 
Table 1

(Continued)

Construct
Knowledge Self-Efficacy
(KSEF)
Kankanhalli et al. [11]
Enjoyment in Helping Others
(EHLP)
Kankanhalli et al. [11]

Generalised Trust (GTRU) Kankanhalli et al. [11]

Pro-Sharing Norms (PSNM) Kankanhalli et al. [11]

Identification (IDEN)

Kankanhalli et al. [11]
- I have confidence in my ability to provide knowledge resources that

(KSEF1) others in the Disaster Management Community consider valuable

- I have the expertise needed to provide valuable knowledge resources for the Disaster Management Community

- It doesn't really make any difference whether I add to the knowledge resources the Disaster Management Community is likely to share

- Most of the other members of the Disaster Management Community can provide more valuable knowledge resources than I can

- I enjoy sharing my knowledge resources with the community

- I enjoy helping the Disaster Management Community by sharing my knowledge resources

- It feels good to help the Disaster Management Community by sharing my knowledge resources

- Sharing my knowledge resources with the Disaster Management Community gives me pleasure

- I believe that people in the Disaster Management Community give credit for other's knowledge resources where it is due

- I believe that people in the Disaster Management Community do not use unauthorized knowledge resources

- I believe that people in the Disaster Management Community use other's knowledge resources appropriately

- I believe that people in the Disaster Management Community share the best knowledge resources that they have

- There is a norm of cooperation in the Disaster Management Community

- There is a norm of collaboration in the Disaster Management Community

(KSEF2)

(KSEF3)

(KSEF4)

(EHLPI)

(EHLP2)

(EHLP3)

(EHLP4)

(GTRU1)

(GTRU2)

(GTRU3)

(GTRU4)

(PSNM1)

(PSNM2)

- There is a norm of teamwork in the Disaster Management Community

(PSNM3)

- There is a willingness to value and respond to diversity in my

(PSNM4)

Community

- There is a norm of openness to conflicting views in my Community

- There is a norm of tolerance of mistakes in the Disaster Management Community

(PSNM5)

(PSNM6)

- I am glad I chose to be a part of the Disaster Management Community

(IDEN1) rather than another Community

- I talk of this Disaster Management Community to my friends as a great Community to be a part of

- I am willing to put in a great deal of effort beyond that normally expected to help the Disaster Management Community to be successful

- I find that my values and the Disaster Management Community's values are very similar

- In general the people in the Disaster Management Community are working toward the same goal

- I find it easy to identify myself with the Disaster Management Community

- I feel that the Disaster Management Community cares about me

(IDEN2)

(IDEN3)

(IDEN4)

(IDEN5)

(IDEN6)

- I feel a sense of belonging towards the Disaster Management Community

(IDEN7)

- I am proud to be a member of the Disaster Management Community 
Table 1

(Continued)

\begin{tabular}{|c|c|c|}
\hline \multirow{3}{*}{$\begin{array}{l}\text { Construct } \\
\text { KB Usage (KBUSG) } \\
\text { Kankanhalli et al. [11] }\end{array}$} & \multicolumn{2}{|l|}{ Item Wording/Measure and Code } \\
\hline & $\begin{array}{l}\text { - What is your frequency of contribution to the knowledge resources of the } \\
\text { community? }\end{array}$ & (KBUSG1) \\
\hline & $\begin{array}{l}\text { - I often contribute my knowledge resources to the Community } \\
\text { - I regularly contribute my knowledge resources to the community }\end{array}$ & $\begin{array}{l}\text { (KBUSG2) } \\
\text { (KBUSG3) }\end{array}$ \\
\hline $\begin{array}{l}\text { The Level of IT Usage } \\
\text { Bock and Kim [1] }\end{array}$ & $\begin{array}{l}\text { - How frequently do you use the following IT to share your knowledge } \\
\text { resources? (5 point Very Rarely - Very frequently) } \\
\text { a. BBS } \\
\text { b. E-Mail } \\
\text { c. Home Page }\end{array}$ & \\
\hline \multirow{4}{*}{$\begin{array}{l}\text { Community-related outcome } \\
\text { expectations (COE) } \\
\text { Chiu et al. [2] }\end{array}$} & $\begin{array}{l}\text { - Sharing my knowledge resources will be helpful to the successful } \\
\text { functioning of the Disaster Management Community }\end{array}$ & (COE1) \\
\hline & $\begin{array}{l}\text { - Sharing my knowledge resources would help the Disaster Management } \\
\text { Community continue its operation in the future }\end{array}$ & (COE2) \\
\hline & $\begin{array}{l}\text { - Sharing my knowledge resources would help the Disaster Management } \\
\text { Community accumulate or enrich knowledge resources }\end{array}$ & (COE3) \\
\hline & $\begin{array}{l}\text { - Sharing my knowledge resources would help the Disaster Management } \\
\text { Community grow }\end{array}$ & (COE4) \\
\hline \multirow[t]{3}{*}{$\begin{array}{l}\text { Shared Vision (SV) } \\
\text { Chiu et al. [2] }\end{array}$} & $\begin{array}{l}\text { - Members of the Disaster Management Community share the vision of } \\
\text { helping others solve their professional problems }\end{array}$ & (SV1) \\
\hline & $\begin{array}{l}\text { - Members of the Disaster Management Community share the same goal } \\
\text { of learning from each other }\end{array}$ & (SV2) \\
\hline & $\begin{array}{l}\text { - Members of the Disaster Management Community share the same value } \\
\text { that helping others is pleasant }\end{array}$ & (SV3) \\
\hline \multirow[t]{6}{*}{$\begin{array}{l}\text { Knowledge quality (KQ) } \\
\text { Chiu et al. [2] }\end{array}$} & $\begin{array}{l}\text { - The knowledge resources shared by members of the Disaster } \\
\text { Management Community are relevant }\end{array}$ & (KQ1) \\
\hline & $\begin{array}{l}\text { - The knowledge resources shared by members of the Disaster } \\
\text { Management Community are easy to understand }\end{array}$ & $(\mathrm{KQ2})$ \\
\hline & $\begin{array}{l}\text { - The knowledge resources shared by members of the Disaster } \\
\text { Management Community are accurate }\end{array}$ & (KQ3) \\
\hline & $\begin{array}{l}\text { - The knowledge resources shared by members of the Disaster } \\
\text { Management Community are complete }\end{array}$ & (KQ4) \\
\hline & $\begin{array}{l}\text { - The knowledge resources shared by members of the Disaster } \\
\text { Management Community are reliable }\end{array}$ & (KQ5) \\
\hline & $\begin{array}{l}\text { - The knowledge resources shared by members of the Disaster } \\
\text { Management Community are timely }\end{array}$ & (KQ6) \\
\hline \multirow[t]{3}{*}{$\begin{array}{l}\text { Shared Language (SL) } \\
\text { Chiu et al. [2] }\end{array}$} & $\begin{array}{l}\text { - Members of the Disaster Management Community use common terms or } \\
\text { jargons }\end{array}$ & (SL1) \\
\hline & $\begin{array}{l}\text { - Members of the Disaster Management Community use understandable } \\
\text { communication patterns during the discussion }\end{array}$ & (SL2) \\
\hline & $\begin{array}{l}\text { - Members of the Disaster Management Community use understandable } \\
\text { narrative forms to post messages or articles }\end{array}$ & (SL3) \\
\hline
\end{tabular}

CRIS is conceptualized to have the following functional components:

- Provides access to DRM and CCA information developed internally by CDEMA and externally by regional and international development partners;

- Maintains a repository of key disaster risk management documents for each CDEMA Participating States including policies, plans, procedures; 
- Provides access to geospatial data with specific focus of demonstrating how risk information can be incorporated into developing hazard specific maps and aid development-oriented planning;

- Maintains project reports to assist in research and information sharing;

A key required technology component of CRIS, therefore, is a document management system (DM) to provide the electronic repository for policies, plans, procedures, reports, standards and other knowledge artifacts. A related initiative to explore new innovative ICT mechanisms [4] led to the development of an alternative technical solution referred to as a knowledge broker $(K B)$. The knowledge broker provides for the integration of silos of knowledge within the disaster management domain, by providing a common semantic reference for knowledge resources and artifacts distributed throughout the region, thus allowing for the emergence of a distributed knowledge commons.

\subsubsection{Comparative institutional analysis - knowledge broker vs document management system}

Our conceptual application of the Knowledge Commons/IAD Framework within this interesting institutional domain seeks to illuminate and inform strategy action, governance and desirable patterns of interactions, as well as the merits of alternative enabling technologies, if the Caribbean Disaster Management community is to realize the goal of enhanced knowledge management and to allow a greater focus on the contingent effects of the enabling ICT infrastructure. As such, we interrogate just a subset of the systematic cluster of inquiries articulated by Frischman et al. [7] in their adapted knowledge commons (IAD) framework. This is consistent with the observation [3] that "efforts to apply the IAD framework in the realm of the information or knowledge commons so far have focused on discrete subparts of the problem or applied only subparts of the IAD framework, which seems sensible and perhaps inevitable". Our focus is therefore on individual actors in "action situations" and the governance mechanisms that will influence their decision-making and actions with respect to desirable outcomes for the CDM knowledge commons. In the interest of space, a brief synopsis of the key aspects of the analysis is presented in Table 2.

\section{Conclusion and future research}

This paper contributes a very preliminary and decidedly limited (deliberately so) application of the Knowledge Commons (IAD) Framework to examine the institutional context for knowledge management within the Caribbean Disaster Management community. Even within this limited scope, the IAD has demonstrated its utility in evaluating key decision issues, especially as it relates to the implementation of the enabling technology platform. The comparative analysis of the knowledge broker, a controlled vocabulary semantic server, as the enabling technology versus more conventional centralized document management systems presents some distinct advantages, especially as it relates to emergent attributes of the knowledge commons, such as openness, modularity and decentralized production, self-management of contributions and infrastructure provisioning.

This case when fully developed is likely to provide additional empirical support for the arguments advanced by [12], challenging the neutrality of infrastructure for collective action. It highlights the importance, and perhaps imperative, of an institutional approach to the design and implementation of socio-technical systems, especially those spanning porous organizational boundaries, versus the typically techno-centric approaches based on the classical Systems Development LifeCycle. The acknowledged failure of prior attempts at implementing similar regional ICT initiatives underscore the need for a different approach that recognizes the importance of institutional design as part of ICT projects to addresses the non-technical social dilemmas that typically confront such initiatives. 
Table 2

Analysis of CDM using the IAD Framework

\begin{tabular}{lll}
\hline $\begin{array}{l}\text { IAD } \\
\text { components }\end{array}$ & \multicolumn{1}{c}{$\begin{array}{c}\text { Definition/ } \\
\text { description }\end{array}$} & \multicolumn{1}{c}{ Questions/narrative - CDM knowledge commons } \\
Actors & $\begin{array}{l}\text { Key members of } \\
\text { the community } \\
\text { participating in the } \\
\text { knowledge } \\
\text { commons }\end{array}$ & $\begin{array}{l}\text { Key Actors in this knowledge commons setting include: CDEMA, the centralized } \\
\text { governing body; the country level agencies responsible for disaster preparedness and } \\
\text { emergency management; National disaster coordinators and representatives of } \\
\text { specialized regional organizations (including Multilateral agencies and Academia), } \\
\text { whose programmes are directly related to the regional disaster management agenda; } \\
\text { organizations/institutions and people working at the local community level. CDEMA, } \\
\text { the designated inter-governmental agency for disaster management in CARICOM, } \\
\text { oversees a comprehensive and mature institutional setting. }\end{array}$
\end{tabular}

Action Decisions \&

situations Actions by

Community members and the

related incentives/outcomes, assessed at various levels of interaction: Constitutional, Collective and Operational

Rules-in-use/ governance mechanisms
The formal rules/informal practices that govern and direct behavior in the knowledge commons
The related strategic Goal is to enhance the information sharing and management of the knowledge generated from various sources, especially the organizations and institutions and people working at the local community level, to increase resilience. A common platform is required that will enable its stakeholders and people to capture, organize, share and reuse relevant knowledge. Achieving this goal will require Actions at several levels, with related incentive mechanisms and governing rules.

Constitutional: Within it's designated authority, the CDEMA Council determines overarching policies and major decisions relating to the community. Mobilizing the knowledge commons requires strong leadership, visioning and advocacy at the highest level

Collective: To induce the institutional change towards a more effective knowledge commons requires a combination of standards, guidelines and incentive mechanisms Operational: At this level, a vibrant knowledge commons will manifest active contributions, sharing and use/reuse of knowledge artifacts by the community

Knowledge resources within the CDM domain include policies, plans, procedures, reports, standards and other reference artifacts. Many of these resources are produced at local community, national, regional and international levels. The technology choices in terms of a centralized document repository versus a distributed knowledge broker that indexes resources wherever they reside, can significantly influence the degree of participation and interaction and ultimately the effectiveness (i.e. of equity, efficiency and sustainability) of the commons.

Openness with respect to the knowledge resources is not a binary state, rather it is a spectrum that exists on multiple-dimensions, specifically: Discoverability, Accessibility, Reusability, and Transparency; Discoverability has been, perhaps, the most evident gap in relation to disaster management knowledge resources in the Caribbean (How do we know what we know?). The absence of a central knowledge authority or directory has severely limited the discoverability of knowledge resources. The knowledge broker has been demonstrated as an effective mechanism for the integration of DRP knowledge silos currently dispersed throughout the region. Openness to community participation in relation to the creation of, rights to, and use of knowledge resources (including access by community outsiders).

The design of the technology platform is also significant in enabling or precluding varying levels of participation access such as standards setting, decentralized production, self-management of contributions, etc. The ability of participants to determine their level of commitment to participation can broaden the community by encouraging more casual contributors.

More formal rules can be established through activities such as document standards (e.g. country/sector-level disaster recovery plans) and well as licensing regimes for knowledge artifacts within the commons. 
The next phase in this research is to administer the survey instrument developed as part of this study to the institutional members of the Caribbean Disaster Management community which includes the National Disaster Coordinators and representatives of specialized regional organizations, whose programs are directly related to the regional disaster management agenda. The researchers anticipate the opportunity to collaborate with CDEMA's Technical Advisory Committee (TAC) to incorporate some of the institutional design considerations arising from this analysis. Ultimately the goal is to ensure that this research and the ongoing engagement with the Caribbean disaster management community can inform and influence the design and implementation of CRIS as a key enabling platform for an effective and sustainable CDM knowledge commons.

\section{References}

[1] G.-W. Bock and Y.-G. Kim, Breaking the myths of rewards: An exploratory study of attitudes about knowledge sharing, in: Pacis 2001 Proc, 2001, p. 78.

[2] C.-M. Chiu, M.-H. Hsu and E.T.G. Wang, Understanding knowledge sharing in virtual communities: An integration of social capital and social cognitive theories, Decis. Support Syst. 42(3) (2006), 1872-1888. doi:10.1016/j.dss.2006.04.001.

[3] D.H. Cole, Learning from Lin: Lessons and Cautions from the Natural Commons for the Knowledge Commons, 2014.

[4] J. Davis, A. Nicholson, L. Rao and M.L. McNaughton, Towards an Open Knowledge Broker for Disaster Recovery Planning in the Caribbean, Uciencia, 2016.

[5] Caribbean Disaster Emergency Management Agency, "Regional Comprehensive Disaster Management Strategy and Programming Framework 2014-2024,", 2014.

[6] B. Fecher and S. Friesike, Open Science: One Term, Five Schools of Thought, 2013, RatSWD Work. Pap.

[7] B.M. Frischman, M.J. Madison and K.J. Strandburg, Governing knowledge commons, in: Governing Knowledge Commons, B.M. Frischmann, M.J. Madison and K.J. Strandburg, eds, Oxford University Press, 2014. doi:10.1093/acprof:oso/ 9780199972036.001.0001.

[8] G. Hardin, The tragedy of the commons, Science 162(3859) (1968), 1243-1248. doi:10.1126/science.162.3859.1243.

[9] C. Hess and E. Ostrom, A Framework for Analyzing the Knowledge Commons: a chapter from Understanding Knowledge as a Commons: from Theory to Practice, 2005.

[10] C. Hess and E. Ostrom, Introduction: An overview of the knowledge commons, in: Knowledge as a Commons: From Theory to Practice, MIT Press, 2006.

[11] A. Kankanhalli, B.C.Y. Tan and K.-K. Wei, Contributing knowledge to electronic knowledge repositories: an empirical investigation, MIS Q. (2005), 113-143. doi:10.2307/25148670.

[12] M.F. Morell, Governance of online creation communities for the building of digital commons: Viewed through the framework of institutional analysis and development, in: Governing Knowledge Commons, Oxford University Press, 2014, p. 281. doi:10.1093/acprof:oso/9780199972036.003.0009.

[13] E. Ostrom, Governing the Commons: The Evolution of Institutions for Collective Action, Cambridge University Press, 1990.

[14] E. Ostrom and C. Hess, Understanding Knowledge as a Commons: From Theory to Practice, MIT Press, 2006.

[15] C.M. Schweik, Toward the Comparison of Open Source Commons Institutions, Gov. Knowl. Commons (2014), $255-279$. doi:10.1093/acprof:oso/9780199972036.003.0008. 